\title{
Rapid-deployment bioprosthetic aortic valve replacement; There is a flag on the field!
}

\author{
Michel Carrier, MD, and Denis Bouchard, $\mathrm{MD}, \mathrm{PhD}$
}

\author{
From the Department of Surgery, Montreal Heart Institute, Montréal, Québec, Canada. \\ Disclosures: Authors have nothing to disclose with regard to commercial support. \\ Received for publication Jan 23, 2018; accepted for publication Jan 31, 2018; available ahead of print March 8, \\ 2018 \\ Address for reprints: Michel Carrier, MD, Montreal Heart Institute, 500 Belanger E, Montréal, Québec H1T 1C8 \\ Canada (E-mail: michel.carrier@icm-mhi.org). \\ J Thorac Cardiovasc Surg 2018;155:2400-1 \\ $0022-5223 / \$ 36.00$ \\ Copyright (c) 2018 by The American Association for Thoracic Surgery \\ https://doi.org/10.1016/j.jtcvs.2018.01.059
}

In the current issue of the Journal, Sohn and colleagues ${ }^{1}$ report the results of a meta-analysis of the literature on the clinical use of rapid-deployment or sutureless bioprostheses. In their analysis, which regrouped data from 21 different clinical studies, 1297 patients who underwent implantation of rapid-deployment or sutureless bioprostheses, essentially the Perceval S (Sorin Group, Milan, Italy) and the Edwards Intuity valve (Edwards Lifescience Corp, Irvine, Calif), were compared with 1488 patients who underwent aortic valve replacement with standard aortic bioprostheses. Only 2 of the studies were true randomized clinical trials. Of interest, the risk of significant bias between the 2 groups was graded as severe or moderate for 19 of the 21 studies included in the meta-analysis. ${ }^{1}$

As expected, patients undergoing implantation of rapiddeployment or sutureless bioprostheses had significantly shorter cardiopulmonary bypass and crossclamp times. In our experience, we also reported shorter operating room and total surgical times., ${ }^{2,3}$ Rates of paravalvular leak appear similar for the 2 groups, but the need for permanent pacemaker insertion was higher in the group undergoing implantation of rapid-deployment or sutureless bioprostheses. Overall, perioperative mortality and morbidity were similar. Sohn and colleagues ${ }^{1}$ concluded that we should be careful because of the higher need for permanent pacemaker implantation after surgery.

The study of Sohn and colleagues ${ }^{1}$ is interesting, but is it really lifting the fog ${ }^{4}$ around these newer rapid-deployment bioprostheses? In fact, data for only 144 from the 2785 $(5 \%)$ studied patients were extracted from randomized trials. The analysis of Sohn and colleagues ${ }^{1}$ is based on heterogeneous groups of patients, different methods of determining prospective and retrospective cohorts, different baseline patient characteristics, and different statistical approaches. Sometimes, summarizing diverse and rather incomplete data leads to more confusion, rather than to clarification.

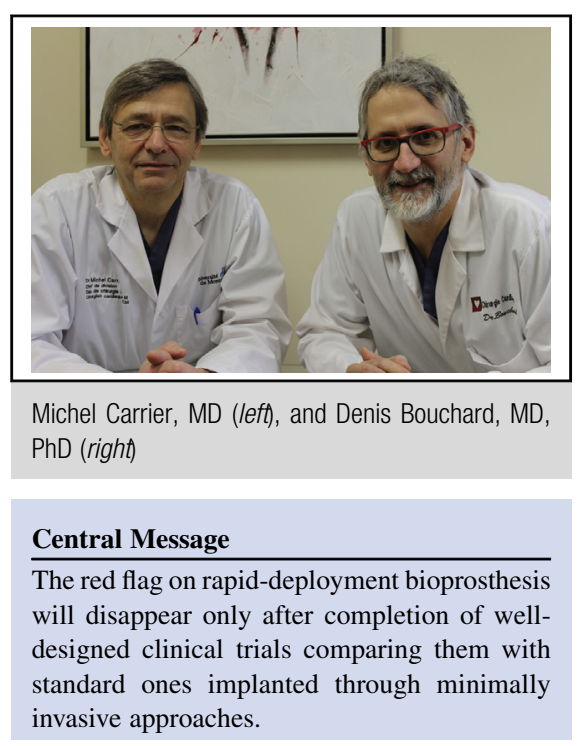

See Article page 2402 .

The use of rapid-deployment and sutureless prostheses not only decreases surgical time but also facilitates minimally invasive approaches, leading to reduced need for blood transfusion, shorter intubation time, and optimal hemodynamic profile. ${ }^{3}$ The higher rate of permanent pacemaker implantation remains an issue in need of proper assessment; is it due to a learning curve with the products, or is it inherent in their design? With the explosion of transcatheter aortic valve replacement, there is a red flag on the field of surgical aortic valve surgery. Clinicians need to innovate; minimally invasive approaches and prostheses facilitating the use of these techniques should be experimented with and tested with appropriate study designs. We should also plan head-to-head comparisons of minimally invasive surgery combined with rapid-deployment prostheses versus transcatheter aortic valve replacement.

The red flag and the fog will disappear only after the completion of well-designed clinical trials that compare rapid-deployment and standard bioprostheses implanted through minimally invasive approaches. The new standard of care in surgical aortic valve replacement may well turn out to be these newer facilitating prostheses! The tipping point toward a change in clinical practice should be based on proper trials in addition to longterm durability data. ${ }^{5}$ 


\section{References}

1. Sohn SH, Jang MJ, Hwang HY, Kim KH. Rapid deployment or sutureless versus conventional bioprosthetic aortic valve replacement: a metaanalysis. J Thorac Cardiovasc Surg. 2018;155:2402-12.e5.

2. Forcillo J, Bouchard D, Nguyen A, Perrault L, Cartier R, Pellerin M, et al. Perioperative outcomes with sutureless versus stented biological aortic valves in elderly persons. J Thorac Cardiovasc Surg. 2016;151: 1629-36.

3. Nguyen A, Stevens LM, Bouchard D, Demers P, Perrault LP, Carrier M. Early outcomes with rapid-deployment vs stented biological valves: a propensity-match analysis. Semin Thorac Cardiovasc Surg. September 8, 2017 [Epub ahead of print].

4. Laufer G, Wiedemann D, Chitwood WR Jr. Rapid-deployment valves: finally the fog is lifting — benefits beyond crossclamp and bypass times. J Thorac Cardiovasc Surg. 2017; 154:1527-31.

5. Glotzbach JP, McKellar SH. Rapid-deployment aortic valves: Do the data support a tipping point? J Thorac Cardiovasc Surg. 2017;154:1532-3. 